Original Article

\title{
APPLICATION OF VALIDATED RP-HPLC METHOD FOR THE DETERMINATION OF ARMODAFINIL IN BULK AND FORMULATION
}

\author{
DEVI RAMESH ${ }^{1}$, MOHAMMAD HABIBUDDIN ${ }^{* 2}$ \\ ${ }^{1}$ Government Polytechnic, Kancharapalem, Visakhapatnam, Andhra Pradesh, 530007 India, ${ }^{2}$ Adept Pharma and Bioscience Excellence \\ Private Limited, Rajivgandhi Nagar, Mooapet, Balanagar, Hyderabad, Telangana, India \\ Email: ramesh_niper@rediffmail.com \\ Received: 22 May 2017, Revised and Accepted: 22 Jul 2017
}

\begin{abstract}
Objective: The objective of the present study is to develop and validate a simple, rapid, sensitive reverse phase HPLC method for the determination of Armodafinil present in bulk and its pharmaceutical formulations.

Methods: The chromatographic separation was achieved by using Hypersil ODS C-18 (150 x $4.6 \mathrm{~mm}, 5 \mu)$ in an isocratic mode with mobile phase methanol: phosphate buffer $3.0(60: 40 \% \mathrm{v} / \mathrm{v})$ was used. The flow rate was $1 \mathrm{ml} / \mathrm{min}$ and effluent was monitored at $225 \mathrm{~nm}$. The method was validated for validation parameters i.e. linearity, accuracy, precision and robustness according to ICH guidelines.
\end{abstract}

Results: The retention time of Armodafinil was $4.2 \mathrm{~min}$ and the linearity range of the method was 500-20000ng/ml with regression ( $\left.\mathrm{r}^{2}\right)$ coefficient 0.9998. The method was validated for precision, accuracy, robustness and which were found to be within the acceptable limits according to the ICH guidelines. Also, the method was successfully applied for the estimation of Armodafinil in the marketed formulation of Nuvigil and the recovery was found to be $>98 \%$.

Conclusion: The developed method possess good selectivity, specificity, there is no interference found in the blank at a retention time of ARM and good correlation between the peak area and concentration of the drugs under prescribed conditions. Hence, the method can be applied for routine analysis of Armodafinil.

Keywords: Armodafinil, Method development, Nuvigil, RP-HPLC, Validation

(C) 2017 The Authors. Published by Innovare Academic Sciences Pvt Ltd. This is an open access article under the CC BY license (http://creativecommons.org/licenses/by/4.0/) DOI: http://dx.doi.org/10.22159/ijcpr.2017v9i5.22162

\section{INTRODUCTION}

Armodafinil (ARM) is a CNS stimulant used for wakefulness in excessive sleepiness associated with obstructive sleep apnoea. It is chemically (-)-2-[(R)-(diphenyl methyl) sulfinyl] acetamide (C15H15NO2S, MW 273.35) [fig. 1]. ARM is a white to off-white, crystalline powder, very slightly soluble in water, sparingly soluble in acetone and soluble in methanol $[1,2]$. ARM is the R-enantiomer of modafinil. Oral administration ARM is readily absorbed. ARM peak concentration $\left(\mathrm{C}_{\max }\right)$ achieved in approximately $2 \mathrm{~h}$; this may be delayed by $2-4 \mathrm{~h}$ if ARM administered with food. But food has no effect on the overall bioavailability of ARM when compared with the fasting state. ARM is eliminated approximately three times more slowly than the S-isomer of racemic modafinil [3].

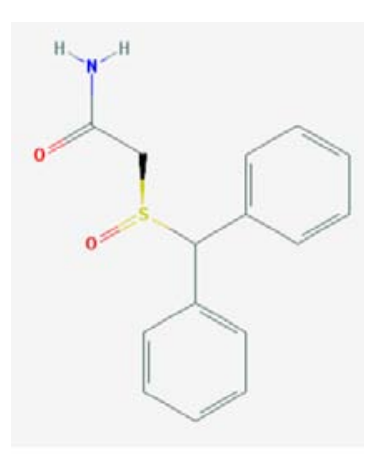

Fig. 1: Chemical structure of armodafinil

There are few methods reported for determination of modafinil in the literature [4-6]. As the ARM is a racemic compound of modafinil, so, determination of modafinil method may (or may not) be applicable for ARM [4-6].

The literature search revealed that there were no HPLC methods reported. Nageshwararao et al. reported enantioselective resolution of synthetic intermediates of ARM along with its related substances [7]. The method was developed by using chiral column and sensitivity was reported at $1540 \mathrm{ng} / \mathrm{ml}$. recently, two methods are reported for ARM in plasma by LC-MS $[8,9]$. Hence, in present investigation, we attempted to develop a novel, simple and economic method for determination of ARM in the formulation by employing the high-pressure liquid chromatography method.

\section{MATERIALS AND METHODS}

Instrumentation

HPLC-Waters 2695 separation module millennium software, Sonicator-Sharp Analytical, Rotary shaker-Vibramax, Analytical balance-Sartorius, Millipore Direct-Q 3 U. V. pH meter-Systronics.

\section{Standards and chemicals}

Armodafinil procured from Matrix laboratories Ltd. (Hyderabad, India), Purified water was prepared using a Millipore Direct-Q 3 U. V with pump water purification system. Acetonitrile of HPLC grade were purchased from Merck Ltd. (Mumbai, India), and o-phosphoric acid of A. R. grade was purchased from Asha chemicals pvt. Ltd (Hyderabad, India), Sodium dihydrogen phosphate of A. R. grade was purchased from Asha chemicals pvt. Ltd (Mumbai, India).

\section{Stock and working solution preparation}

Preparation of standard stock solution: Accurately weighed and transferred $50 \mathrm{mg}$ of ARM into a $50 \mathrm{ml}$ volumetric flask dissolved and made up of the volume with methanol. Daily working standard solutions of ARM was prepared by suitable dilution of the stock solution with mobile phase. 
Preparation of buffer: $20 \mathrm{mmol}$ strength of phosphate buffer is prepared by using $620 \mathrm{mg}$ of potassium dihydrogen phosphate in 500 ml HPLC grade water adjust to $\mathrm{pH} 3.0$ by using orthophosphoric acid.

\section{Method validation}

The validation parameters like linearity, sensitivity, accuracy, precision, recovery and stability, according to the ICH guidelines were carried [10].

Selectivity is studied by comparing the chromatograms obtained from placebo sample with the chromatogram obtained from the tablet. Calibration curves are prepared by assaying standard samples of the drug, ranging from $500-20000 \mathrm{ng} / \mathrm{ml}$. The linearity of the method was determined by plotting the peak area $(y)$ of drug versus the nominal concentration $(x)$ of the drug. The calibration curves are constructed by least squares linear regression.

Intra-and inter-day accuracy and precision of this method was determined at three different concentration levels in 3 different days. On each day, three replicates were analyzed with independently prepared calibration curves. The accuracy and precision were expressed as percentage accuracy and relative standard deviation (R. SD, \%) respectively and calculated by using equations (1) and (2).

$$
\begin{aligned}
& \text { Accuracy }(\%)=\frac{\text { Mean observed concentration }}{\text { Nominal concentration }} \times 100 \\
& \% \mathrm{RSD}=\frac{\text { Standard deviation }}{\text { Mean }} \times 100 \\
& \text { Eq. (2) }
\end{aligned}
$$

The limit of detection (LOD) and limit of quantification (LOQ) are defined as the lowest concentration giving a signal-to-noise ratio $(\mathrm{S} / \mathrm{N})$ of at least $3: 1$ and $10: 1$ respectively.

The stability of the drug solution was determined for short-term (solution stability) by keeping at room temperature $\left(25^{\circ} \mathrm{C}\right)$ for $24 \mathrm{~h}$. Auto sampler stability was determined by storing the samples for 24 $\mathrm{h}$ in the auto sampler. Each sample injected three times into HPLC and concentrations obtained were compared with the nominal values of the QC samples.

\section{Analysis of dosage form}

20 Tablets (100 mg and $250 \mathrm{mg}$ ) each separately, were weighed, finely powdered and an accurately weighed sample of powdered tablets equivalent to one tablet was transferred into $100 \mathrm{ml}$ volumetric flask and drug was extracted with methanol. This solution was filtered through Whatmann No.1 filter paper and solution obtained was diluted with the mobile phase so as to obtain a concentration in the range of linearity previously determined. The sample was injected in five times into HPLC. The amount of drug recovered was calculated from the linearity graph.

\section{RESULTS AND DISCUSSION}

\section{Method development}

\section{Method optimization}

The chromatographic method was optimized by changing various parameters, such as $\mathrm{pH}$ of the mobile phase, organic modifier and buffer used in the mobile phase and composition of the mobile phase. Water and phosphate buffer in various strengths are tried along with methanol and acetonitrile as organic solvent. A mixture of methanol and phosphate buffer ( $\mathrm{pH} 3.0$ ) was tested as a mobile phase with Hypersil ODS C-18. Increasing the composition of organic phase decrease in retention time, the peak shape of drugs was poor and shoulder peak was observed. The retention time was increased with the reducing the organic phase percentage in the mobile phase. The mobile phase composition of 60:40 v/v methanol: buffer was given good resolution, retention time with a minimal tailing factor in acceptable range. The method was optimized with the mobile phase composition of methanol and phosphate buffer $60: 40(\mathrm{v} / \mathrm{v})$.

Buffer molarity of 10,20 and $50 \mathrm{mmol}$ was tested. There were no significant changes in the chromatographic response and peak shape with change in buffer molarity. A buffer molarity of $20 \mathrm{mmol}$ was selected for further analysis.

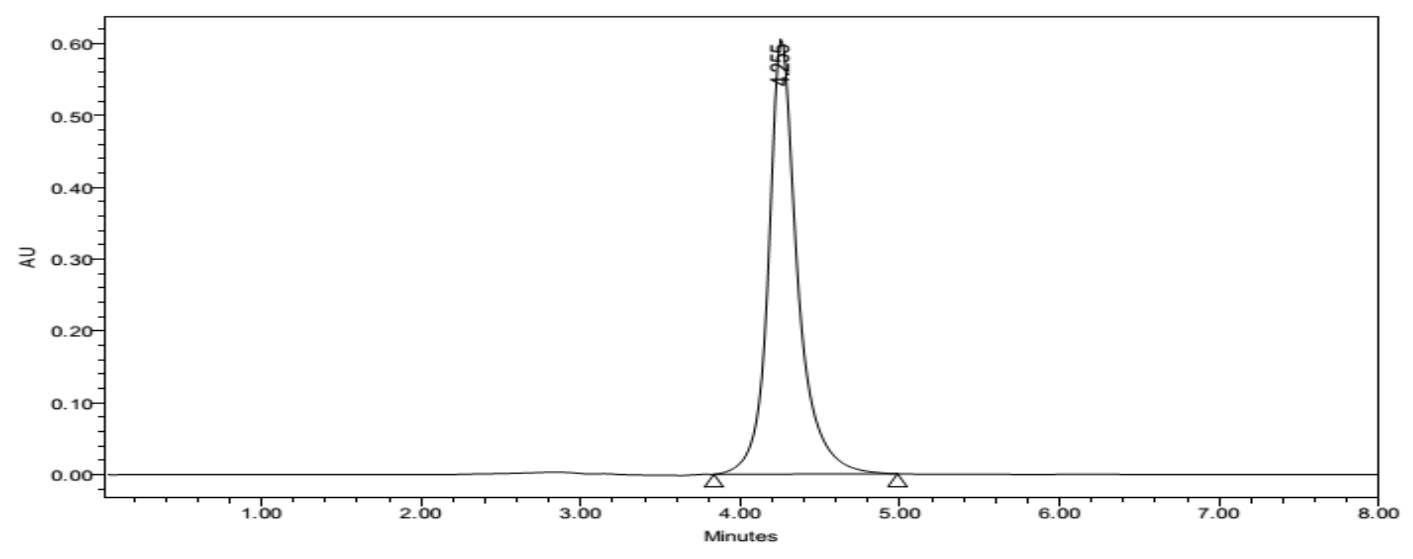

Fig. 2: Standard chromatogram of armodafinil

After several trials, the method was optimized as a mixture of 20 mmol potassium dihydrogen phosphate buffer $(\mathrm{pH} 3.0)$ and methanol (40:60 v/v), at a flow rate of $1 \mathrm{ml} / \mathrm{min}$, at $225 \mathrm{~nm}$ for run time $8 \mathrm{~min}$. These chromatographic conditions achieved a satisfactory resolution, retention time and tailing for ARM. The [fig. 2] shows that standard chromatogram of ARM.

\section{System suitability}

To check the system suitability, working stock standard of individual drugs were injected HPLC to determine the individual retention times of drugs. Then working standard solution was injected five times and we considered relative standard deviation (RSD) for five consecutive injections $\leq 2$, the resolution between two adjacent peaks $\geq 2$ and tailing factor $<2$ acceptable values [11]. Resolution (R), relative standard deviation from five replicate injections of working standard mixture solution, tailing factor $(\mathrm{T})$ and retention time drug was presented in [table 1]. System suitability test confirmed that the chromatographic system was adequate for the analysis planned to be done.

\section{Method validation}

\section{Selectivity}

The selectivity of the present method is established by checking the blank sample and observed the chromatogram. There is no interference found at retention time ARM in the blanks concludes the selectivity of the method. 
Table 1: System suitability parameters of ARM

\begin{tabular}{lll}
\hline Parameters $(\mathbf{n}=\mathbf{5})$ & Results & Required limits \\
\hline Retention time in minutes $\left(\mathrm{R}_{\mathrm{t}}\right)$ & $4.22 \pm 0.01,0.36$ & $\mathrm{RSD} \leq 2$ \\
Theoretical plates $(\mathrm{N})$ & $5756 \pm 64,1.12$ & $\mathrm{~N}>2000$ \\
Tailing Factor $(\mathrm{T})$ & $1.17 \pm 0.01,1.48$ & $\mathrm{~T} \leq 2$ \\
\hline
\end{tabular}

\section{Linearity}

The linearity of this method is evaluated by linear regression analysis, which is calculated by the least square method and the drug is linear in the concentration range of 500-20000 $\mathrm{ng} / \mathrm{ml}$. Calibration standards are prepared by spiking required volume of working standard $(100 \mu \mathrm{g} / \mathrm{ml})$ solution into different $10 \mathrm{ml}$ volumetric flasks and volume made up with methanol to yield concentrations of 500, 1000, 2000, 5000, 10000, and $20000 \mathrm{ng} / \mathrm{ml}$ of ARM. The resultant peak area of the drug was measured. The calibration curve is plotted between peak areas of the drug against the concentration of the drug. The [fig. 3] shows the linearity graph regression coefficient $\left(\mathrm{r}^{2}\right)$ including the slope and y-intercept.

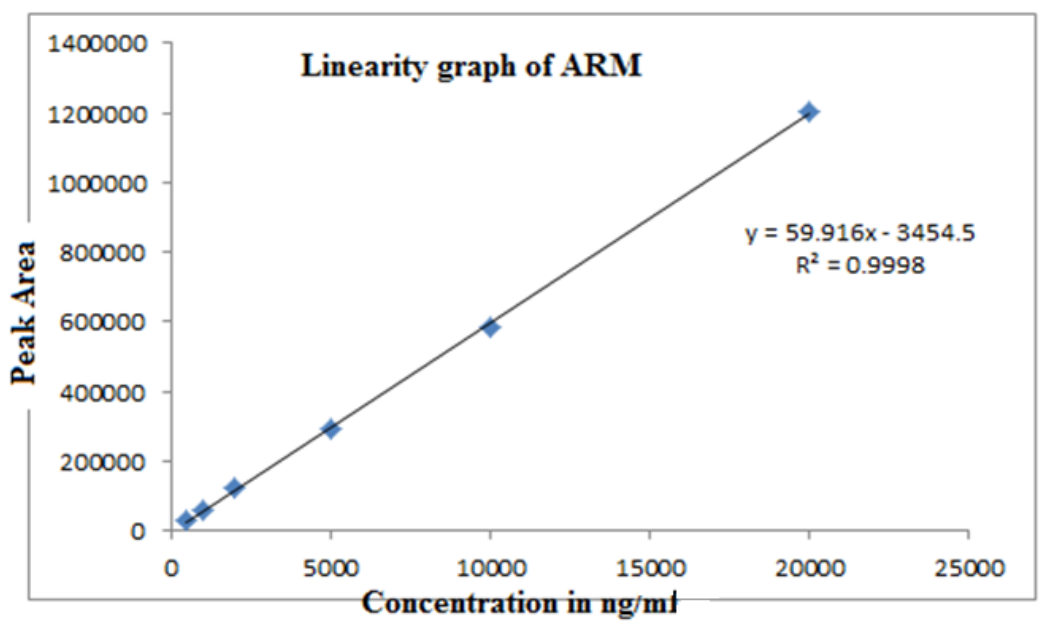

Fig. 3: Linearity graph of armodafinil

\section{Sensitivity}

The limit of detection (LOD) and limit of quantification (LOQ) are defined as the lowest concentration giving a signal-to-noise ratio of at least 3-fold and 10-fold, respectively. The LOD and LOQ of this method were verified based on the standard deviation of response and slope and found to $144.74 \mathrm{ng} / \mathrm{ml}$ and $438.62 \mathrm{ng} / \mathrm{ml}$ respectively.

\section{Intra-day and Inter-day precision and accuracy}

The intra-and inter-day precision and accuracy of this method is determined by analyzing replicates of QC samples at three concentrations on 3 different days. The coefficients of variation for the intra-and inter-day precision were $<2 \%$. The intra-and inter-day accuracies are $95.80-104.56 \%$. The low levels of coefficients of variation $(0.18 \%-1.85 \%)$ [table 2], indicate the method is accurate and precise.

\section{Robustness}

Robustness of the method was done by changing slight variation in the parameters like mobile phase composition, flow rate and wavelength. Present method didn't show any significant change when the critical parameters were modified. The tailing factor of drug was always less than 2.0 and the components were well separated under all the changes carried out. Considering the modifications in the system suitability parameters and the specificity of the method, as well as carrying the experiment at room temperature may conclude that the method conditions were robust.

\section{Ruggedness}

Ruggedness is studied along with precision and accuracy of batches where the effect of the column, and analyst change are observed. The observed value for column variation and results obtained for precision and accuracy are within the acceptance criteria (i.e. there are no changes in the retention time, recovery and precision of the drug) according to ICH [10].

\section{Stabilities}

The stability of drug was studied at different conditions for quality control (QC) of samples. The samples were analyzed and compared with freshly analyzed QC samples, no difference were found in accuracy and precision concludes that there was no degradation of drugs during the analysis.

\section{Application of method for assay of dosage form}

Amount of the drug in the formulation has been determined and the percentage recovery was found to be $>98.21 \%$. The data were shown in [table 3]. The [fig. 3], shows the chromatogram of ARM from formulations.

Table 4: Intra and inter-day accuracy and precision of ARM

\begin{tabular}{llll}
\hline Concentration $(\mathbf{n g} / \mathbf{m l})$ & Intra-day (n=6) & Inter-day (n=9) \\
\cline { 2 - 4 } & mean+SD & RSD (\%) & mean \pm SD \\
\hline 1500 & $104.62 \pm 0.55$ & 0.53 & $104.56 \pm 1.20$ \\
8000 & $98.12 \pm 1.34$ & 1.36 & $95.80 \pm 1.77$ \\
15000 & $100.16 \pm 0.40$ & 0.40 & $99.32 \pm 0.18$ \\
\hline
\end{tabular}

Values expressed mean \pm SD 
Table 3: Recovery study from formulation $(n=5)$ of ARM

\begin{tabular}{|c|c|c|c|}
\hline Brand name & Labeled amount(mg) & Calculated amount (mg) \pm SD & Assay (\%) \\
\hline Nuvigil & $\begin{array}{l}100 \\
250\end{array}$ & $\begin{array}{l}98.21 \pm 0.76 \\
252.54 \pm 1.07\end{array}$ & $\begin{array}{l}98.21 \\
100.98\end{array}$ \\
\hline
\end{tabular}

Values are expressed in mean $\pm \mathrm{SD}, \mathrm{n}=5$

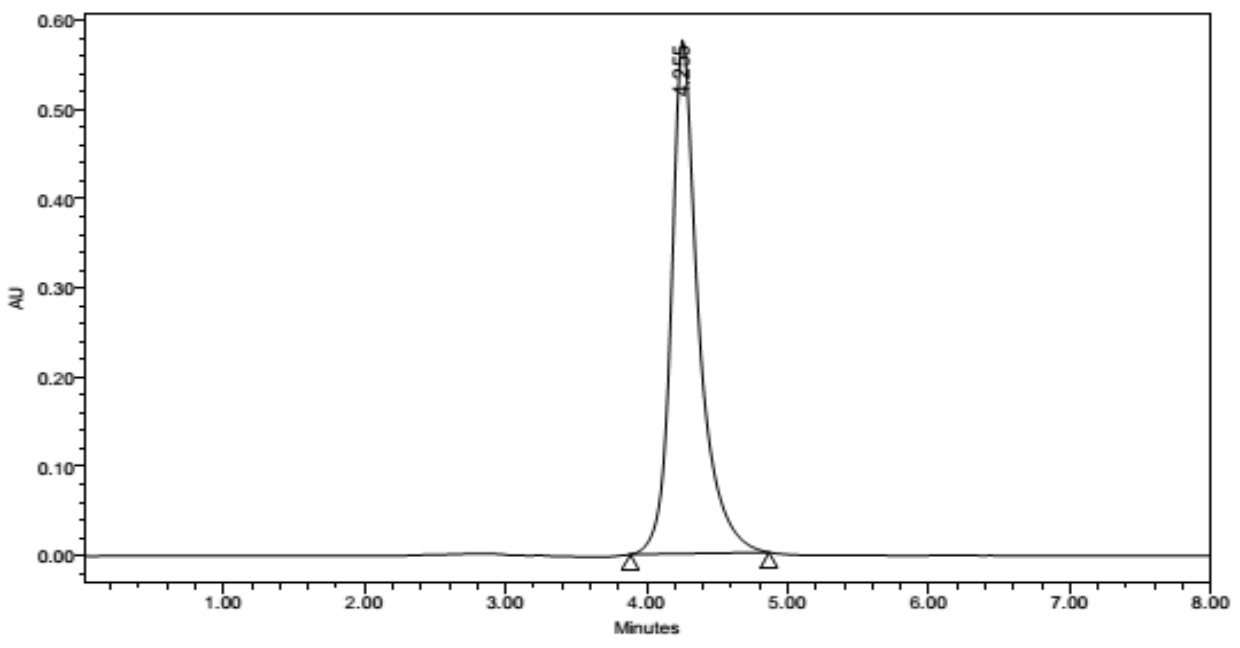

Fig. 4: Chromatogram of armodafinil from formulation

\section{CONCLUSION}

The developed method possess good selectivity, specificity, there is no interference found in the blank at a retention time of ARM and good correlation between the peak area and concentration of the drugs under prescribed conditions and also the accuracy of the was found to be $>95.80 \%$. The observation of $\%$ RSD less than 2 for both intra-and inter-day measurements also indicates a high degree of precision. In the present method, a Hypersil ODS, C-18 column has been used at flow rate of $1 \mathrm{ml} / \mathrm{min}$ and $\mathrm{pH} 3.0$. A linearity range of $500-20000 \mathrm{ng} / \mathrm{ml}$ ARM; this linearity range covers all the strengths of ARM. The method was successfully applied for analysis of ARM from its formulation and also it can be helpful for further investigative studies ARM.

\section{ACKNOWLEDGEMENT}

Author is thankful to Adept Pharma and Bioscience Excellence Private Limited for providing all types of facilities for the research.

\section{CONFLICT OF INTERESTS}

The authors report no conflicts of interest. The authors alone are responsible for the content and writing of the paper.

\section{REFERENCES}

1. Charles AC, James KW, Keith AW, Sanjay A, Thomas R. Armodafinil for treatment of excessive sleepiness associated with shift work disorder: a randomized controlled study. Mayo Clin Proc 2009;84:958-72.

2. Russo M. Pharmacotherapy of excessive sleepiness: focus on armodafinil. Clin Med Ther 2009;1:415-32.

3. Mona D, Mary K, Edward TH, Ronghua Y, Philmore R. Pharmacokinetic profile of armodafinil in healthy subjects.
Pooled analysis of data from tree randomized studies. Clin Drug Invest 2009;29:87-100.

4. Schwertner HA, Kong SB. Determination of modafinil in plasma and urine by reversed phase high-performance liquid chromatography. J Pharm Biomed Anal 2005;9:475-9.

5. Gorman SH. Determination of modafinil, modafinil acid and modafinil sulfone in human plasma utilizing liquid-liquid extraction and high-performance liquid chromatography. J Chromatogr B: Anal Technol Biomed Life Sci 2002;767:269-76.

6. Musuku A, Sojo LE, Chee P, Lum G, Axelson JE. Development and validation of a liquid chromatography mass spectrometry assay method for the determination of modafinil in human plasma. AAPS J 2011;73:558-63.

7. Nageshwararao $R$, Shinde DD, Kumar Talluri MVN. Enantioselective HPLC resolution of synthetic intermediates of armodafinil and related substances. J Sep Sci 2008;31:981-9.

8. Mamta PD, Anandan P, Arindam M. Development of rapid and sensitive method for estimation of armodafinil in human plasma by LC/MS/MS. Int J Appl Biol Pharm Technol 2011;2:323-7.

9. Devi Ramesh, Singirikonda Ramakrishna, Mohammad Habibuddin. Development and validation of new LC-MS/MS method for the determination of armodafinil in human plasma. Curr Pharm Anal 2012;8:295-305.

10. ICH, Q2B. Harmonized tripartite guideline, validation of analytical procedure: methodology, IFPMA, in: Proceedings of the International Conference on Harmonization; 1996.

11. USP (The United States pharmacopoeia convention) 30-NF 25, Rockville MD. 2007. p. 1005, 1776.

\section{How to cite this article}

- Devi Ramesh, Mohammad Habibuddin. Application of the validated RP-HPLC method for the determination of armodafinil in bulk and formulation. Int J Curr Pharm Res 2017;9(5):158-161. 